Article

\title{
Hierarchical Manganese-Iron-Layered Double Hydroxide Nanosheets for Asymmetric Supercapacitors
}

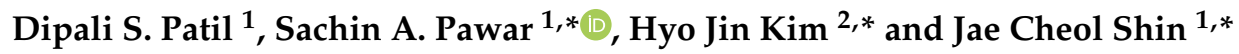 \\ 1 Department of Physics, Yeungnam University, Gyeongsan, Gyeongbuk 38541, Korea; \\ dipali.patilphy@gmail.com \\ 2 Korea Photonics Technology Institute, Buk-gu, Gwangju 61007, Korea \\ * Correspondence: sachinpawar69@gmail.com (S.A.P.); hjk@kopti.re.kr (H.J.K.); jcshin@yu.ac.kr (J.C.S.)
}

Received: 31 July 2020; Accepted: 1 September 2020; Published: 4 September 2020

check for updates

\begin{abstract}
This work presents a synthesis of hierarchical manganese-iron-layered double hydroxide (MnFe-LDH) nanostructured electrodes using the hydrothermal synthesis route by varying the reaction time for electrochemical energy storage applications. The electrochemical behavior of the $\mathrm{MnFe-LDH}$ electrodes synthesized at different reaction times was analyzed in a three-electrode cell configuration using $2 \mathrm{M} \mathrm{KOH}$ electrolyte. The uniform and well-organized MnFe-LDH nanosheet electrode (MnFe-12h) showed the maximum areal capacitance of $2013 \mathrm{mFcm}^{-2}$ at a $5 \mathrm{mVs}^{-1}$ scan rate, and $1886 \mathrm{mFcm}^{-2}$ at a $25 \mathrm{~mA}$ applied current. Furthermore, the electrochemical behavior of MnFe-12h was examined by assembling an asymmetric cell device using activated carbon (AC) as a negative electrode and $\mathrm{MnFe}-12 \mathrm{~h}$ as a positive electrode and it was tested in a wide voltage window range of 0.0 to $1.6 \mathrm{~V}$. This asymmetric cell device achieved an appropriate energy density of $44.9 \mu \mathrm{W} \mathrm{h} \mathrm{cm}{ }^{-2}$ $\left(55.01 \mathrm{~W} \mathrm{~h} \mathrm{~kg}^{-1}\right)$, with a power density of $16 \mathrm{~mW} \mathrm{~cm}^{-2}\left(5000 \mathrm{~W} \mathrm{~kg}^{-1}\right)$ at an applied current of $10 \mathrm{~mA}$, and had a long-term cycling stability ( $93 \%$ capacitance retention after 5000 cycles) within the $1.6 \mathrm{~V}$ operating voltage window.
\end{abstract}

Keywords: MnFe; layered double hydroxide; asymmetric supercapacitor; hydrothermal

\section{Introduction}

The current global situation due to climate change demands green energy alternatives such as renewable energies in order to preserve our ecosystem. It is highly essential to store these renewable energies to be able to use them on demand. Supercapacitors (SCs), also known as ultracapacitors owing to their high capacitance, are the most appealing energy storage systems. The fast charge-discharge rate, good cycling stability, high power density, low cost, and eco-friendliness of SCs is the reason why people are turning their attention to them [1-3]. The charge storage mechanisms in SCs classify them as electric double-layer capacitors (EDLCs) and pseudocapacitors. In EDLCs, the adsorption/desorption of electrolytic ions takes place in the space charge double-layer region of the material, leading to limited energy density. In pseudocapacitors, the energy can be stored to a greater degree due to the faradaic charge transfer process $[4,5]$.

Layered double hydroxides (LDHs) have attracted much attention as an electrode material for supercapacitors owing to their high surface area, high redox activity, highly interconnected morphology, low cost, and environmental benignness [6,7]. The hydroxide layers in the LDH structure contain positive charges and anions among the layers. LDHs possess flexible anionic exchange and a laminar structure that helps electron and ion transport during the charging/discharging process in SCs [8]. Additionally, the hydrophilicity in LDHs is highly favorable for the diffusion of ions in aqueous electrolyte. 
Among the various $\mathrm{LDH}$ structures, NiAl-LDH, NiCo-LDH, MnCo-LDH, and NiFe-LDH structures are widely used as supercapacitor electrodes as well as for catalysis applications [9-12]. Bagavathi et al. fabricated Co-Ni LDH using the electrophoretic deposition technique, which produced a specific capacitance of $1931 \mathrm{Fg}^{-1}$ [13]. They synthesized these nanostructures without any aid from additives and binders. In a recent effort, Tyagi et al. synthesized a less explored Ni-V LDH structure using the hydrothermal route, which showed a specific capacitance of $1581 \mathrm{Fg}^{-1}$ [14]. Wang et al. reported a specific capacitance of $2762.7 \mathrm{Fg}^{-1}$ for Ni-Co LDH from 2-methylimidazole by varying the $\mathrm{Ni} / \mathrm{Co}$ ratio as 4:1 [8]. In an attempt to synthesize a ternary LDH hybrid for a supercapacitor, Li et al. fabricated NiMnCr-LDH coated on a carbon sphere, which yielded a specific capacity of $569 \mathrm{C} \mathrm{g}^{-1}$ at $3 \mathrm{Ag}^{-1}$ [15]. An asymmetric supercapacitor was fabricated by $\mathrm{Li}$ et al. based on a $(\mathrm{Ni}, \mathrm{Co}) \mathrm{Se} 2 / \mathrm{NiCo}-\mathrm{LDH}$ core-shell with a specific capacitance of $1224 \mathrm{Fg}^{-1}$ [16]. The aforementioned results in the literature affirm the potential of LDH structures as an electrode material for pseudocapacitors and asymmetric supercapacitors.

Despite the fact that many LDH composites are involved in supercapacitor studies, MnFe-LDH is a versatile electrode material for pseudocapacitor studies as it can replace the carbon-based supercapacitor that is capable of producing a high energy density. In the MnFe-LDH structure, the introduction of manganese helps to improve the electrochemical activity due to its multiple oxidation states. Similarly, Fe was incorporated into the LDH composite because the Fe ions in the host layers can deliver numerous redox reactions during the electrochemical process, as well as the fact that iron is much cheaper than other metals such as cobalt and aluminum and is plentiful in nature [17,18]. MnFe-LDH can be grown using different chemical synthesis routes such as electrospinning, co-precipitation, hydrothermal synthesis, etc., and it is being used for multiple applications [19-22]. So far, MnFe-LDH has found its application in MRI contrast enhancement, drug release, and oxygen evolution catalysts, among others. Furthermore, it is surprising to learn that no study has been reported on MnFe-LDH for supercapacitor studies [20,22].

Herein, we propose a first attempt to fabricate a MnFe-LDH structure for a supercapacitor study using a simple and scalable hydrothermal synthesis route. MnFe-LDH electrodes were synthesized by varying the hydrothermal reaction time from 9 to $24 \mathrm{~h}$ and the electrochemical behavior was analyzed in a three-electrode cell configuration using $2 \mathrm{M} \mathrm{KOH}$ electrolyte. A maximum areal capacitance of $2013 \mathrm{mFcm}^{-2}$ at a $5 \mathrm{mVs}^{-1}$ scan rate and $1886 \mathrm{mFcm}^{-2}$ at a $25 \mathrm{~mA}$ applied current were achieved for the uniform and well-organized MnFe-LDH nanosheet electrode (MnFe-12h). Moreover, an asymmetric cell device using activated carbon as a negative electrode and $\mathrm{MnFe}-12 \mathrm{~h}$ as a positive electrode was assembled and tested in a wide voltage window range of 0.0 to $1.6 \mathrm{~V}$. This asymmetric cell device achieved an appropriate energy density of $44.9 \mu \mathrm{W} \mathrm{h} \mathrm{cm}-2\left(50.01 \mathrm{~W} \mathrm{~h} \mathrm{~kg}^{-1}\right)$, with a power density of $16 \mathrm{~mW} \mathrm{~cm}^{-2}\left(5000 \mathrm{~W} \mathrm{~kg}^{-1}\right)$ at an applied current of $10 \mathrm{~mA}$, and had a long-term cycling stability $(93 \%$ capacitance retention after 5000 cycles) within the $1.6 \mathrm{~V}$ operating voltage window.

\section{Experimental Details}

\section{Synthesis of MnFe-LDH Hexagonal Sheets}

MnFe-LDH was deposited on Ni foam using a facile hydrothermal technique. The solution for the hydrothermal reaction was first prepared using different precursor solutions. The manganese precursor $\left(0.01 \mathrm{M} \mathrm{KMnO}_{4}\right)$, iron precursor $\left(0.01 \mathrm{M} \mathrm{FeSO}_{4}\right)$, and $0.01 \mathrm{M}$ urea were dissolved in $60 \mathrm{~mL}$ deionized (DI) water in a $100 \mathrm{~mL}$ glass beaker and stirred for $15 \mathrm{~min}$. The obtained mixture was then poured into a $100 \mathrm{~mL}$ Teflon-lined stainless steel autoclave. Subsequently, the Ni foam was placed deep into the mixture. The hydrothermal reaction was carried out in an oven at $140{ }^{\circ} \mathrm{C}$ for $9 \mathrm{~h}$. Finally, the hydrothermal autoclave was brought down to room temperature naturally. DI water was used to wash the Ni foam and it was air-dried. The prepared electrode was marked as MnFe-9h. Similarly, the hydrothermal reactions were carried out for 12 and $24 \mathrm{~h}$ and the samples were marked as MnFe- $12 \mathrm{~h}$ and $\mathrm{MnFe}-24 \mathrm{~h}$, respectively. 


\section{Characterization of Electrodes}

X-ray diffraction (XRD; Panalytical, Malvern, UK) was performed using $\mathrm{Cu}$ K $\alpha$ radiation. X-ray photoelectron spectroscopy (XPS; K-alpha, Thermo Scientific, Loughborough, UK) was used to govern the surface chemical composition. The surface features of the film were analyzed by field-emission scanning electron microscopy (FESEM; S-4800 HITACHI, Ltd., Tokyo, Japan). Electrochemical measurements, including cyclic voltammetry (CV), electrochemical impedance spectroscopy (EIS), and galvanostatic charge/discharge (GCD) measurements, were performed in $2 \mathrm{M} \mathrm{KOH}$ electrolyte in a conventional three-electrode arrangement consisting of synthesized $\mathrm{MnFe}-\mathrm{LDH}$ as a working electrode, graphite as a counter electrode, and saturated calomel as a reference electrode (SCE) using a ZIVE SP5 electrochemical workstation (WonAtech, Seoul, Korea). For each electrode, the area of the deposited MnFe-LDH was constant $(1 \mathrm{~cm} \times 1 \mathrm{~cm})$. For the two electrode measurements, an asymmetric cell device was fabricated using MnFe-12h as a positive electrode and activated carbon (AC) as a negative electrode. The AC electrode was prepared as mentioned in our previous report [18]. Briefly, to prepare the AC electrode, the activated carbon, binder poly (tetrafluoroethylene), and carbon black in a weight ratio of 80:10:10 were mixed together. The obtained mixture was coated onto the $\mathrm{Ni}$ foam and then air-dried at $75{ }^{\circ} \mathrm{C}$ for $12 \mathrm{~h}$. The device was assembled by inserting filter paper soaked in $2 \mathrm{M} \mathrm{KOH}$ between the positive (MnFe-12h) and negative (AC) electrodes and sealed using Parafilm. The detailed schematic representation of the asymmetric device fabrication is as shown in Figure $1 \mathrm{~b}$.

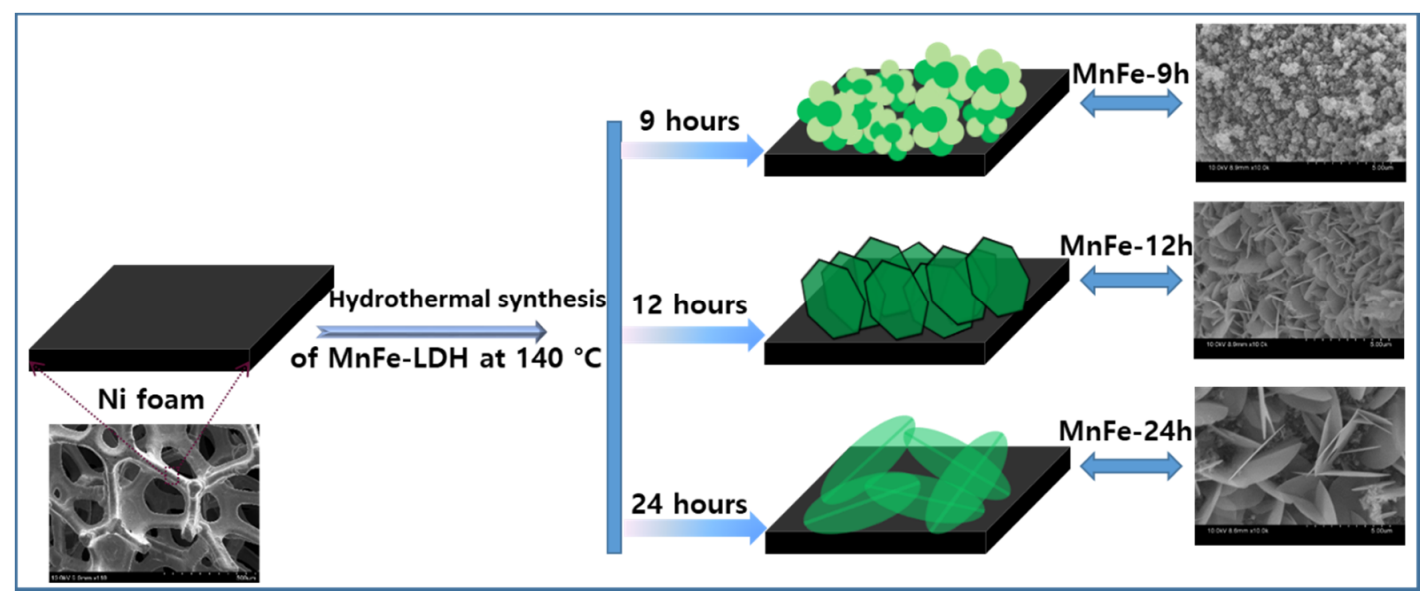

(a)

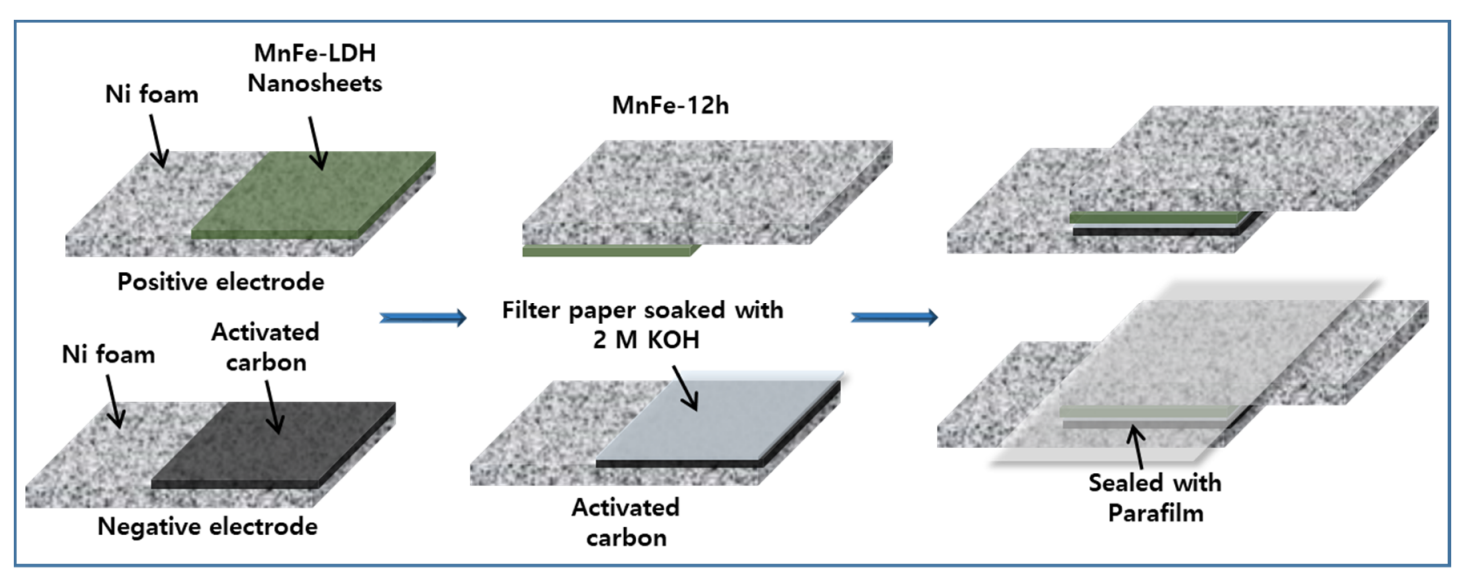

(b)

Figure 1. Schematic illustrations of the (a) stepwise growth process of MnFe hydroxide nanostructures controlled by the hydrothermal reaction time. (b) Fabrication of the asymmetric cell device. 


\section{Results and Discussion}

The schematic illustration of the formation of different nanostructures of MnFe-LDH using the hydrothermal route with varying reaction times is depicted in Figure 1a. The hydrothermal reaction mainly comprises the hydrolysis of urea $\left(\mathrm{CO}\left(\mathrm{NH}_{2}\right)_{2}\right.$, which produces $\mathrm{OH}^{-}$ions. These released $\mathrm{OH}^{-}$ions interact with the dissociated $\mathrm{Mn}^{2+}$ and $\mathrm{Fe}^{2+}$ ions from $\mathrm{KMnO}_{4}$ and $\mathrm{FeSO}_{4}$, respectively, forming $\mathrm{MnFe}-$ hydroxide [11,17]. The probable chemical reactions happening during the formation of MnFe-hydroxide through hydrothermal treatment can be signified by the following reactions:

$$
\begin{gathered}
\mathrm{CO}\left(\mathrm{NH}_{2}\right)_{2}+\mathrm{H}_{2} \mathrm{O} \rightarrow 2 \mathrm{NH}_{3}+\mathrm{CO}_{2} \\
\mathrm{NH}_{3}+\mathrm{H}_{2} \mathrm{O} \rightarrow \mathrm{NH}_{4}^{+}+\mathrm{OH}^{-} \\
\mathrm{Mn}^{2+}+\mathrm{Fe}^{2+}+\mathrm{OH}^{-} \rightarrow \mathrm{MnFe}-\mathrm{LDH}
\end{gathered}
$$

\subsection{FESEM}

The surface morphological features of the MnFe-LDH electrode were studied by FESEM. Figure 2a-1 shows FESEM images of the MnFe-9h, MnFe- $12 \mathrm{~h}$ and MnFe-24h samples. In the FESEM images at lower magnification (Figure 2a,e,i), it is clearly seen that the Ni foam's surface is fully covered by the synthesized MnFe-LDH material, for all synthesized electrodes grown at 9, 12, and $24 \mathrm{~h}$, respectively. Initially, after a $9 \mathrm{~h}$ hydrothermal reaction, an aggregation of nanoparticles of the MnFe-LDH structure appears, as shown in Figure 2a-d, and a partial growth of the nanosheet is also observed. As the reaction time goes on, increasing to $12 \mathrm{~h}$, the nanoparticle aggregates are turned into a network of interconnected nanosheets (Figure 2e-h). These MnFe-LDH nanosheets appear in a bunch resembling petals of a flower. It should be noted that the large number of even and dense MnFe-LDH nanosheets is seen firmly anchored on the whole surface of the Ni foam. The nanosheets are very thin, with an average thickness of $\sim 15-20 \mathrm{~nm}$. The thin and interconnected nanosheets are highly beneficial for ionic transport, mainly due to their enhanced reactive surface area. Similarly, the layered structure of LDHs offers an easy access to electrolyte ions to diffuse through the entire nanosheet, which is useful for a highly efficient utilization of active sites [23]. Finally, for the $24 \mathrm{~h}$ hydrothermal reaction time, the formation of large leaf-like nanostructures with voids in between these nanostructures is observed (Figure 2i-1); this may be due to the higher reaction time. Figure 3a-d shows the EDS elemental mapping of the MnFe-LDH electrode, affirming the presence of the elements $\mathrm{Mn}, \mathrm{Fe}$, and $\mathrm{O}$. The green regions in the images are the manganese-containing regions (Figure $3 b$ ), red regions belong to the iron distribution (Figure 3b), whereas the cyan region indicates the presence of the oxygen-containing portions (Figure $3 c$ ) of the MnFe-12h electrode.

\section{2. $X R D$}

The crystal structure and phase of a MnFe-LDH nanostructure are determined by an X-ray diffraction study; Figure 4a presents the XRD patterns of the MnFe-LDH structure of the MnFe-9h, $\mathrm{MnFe}-12 \mathrm{~h}$, and MnFe-24h samples. The XRD patterns show a series of (001) reflections characteristic of layered structures, affirming the LDH structure of MnFe-LDH. The peaks correspond to the (003), (006), and (009) planes of the MnFe-LDH structure, which again confirms the formation of the MnFe-layered structure. The nature of XRD peaks is broad, indicating a nanocrystallinity of the MnFe-LDH structure. Similar peaks were obtained for MnFe-LDH elsewhere [20,24]. Apart from the peaks due to MnFe-LDH, there are sharp peaks at $44^{\circ}, 52^{\circ}$, and $76^{\circ}$, which are assigned to the Ni foam substrate, denoted by " $\Delta$ ". In addition, some peaks are detected, ascribed to the precursors used for the preparation of the electrodes [18]. 


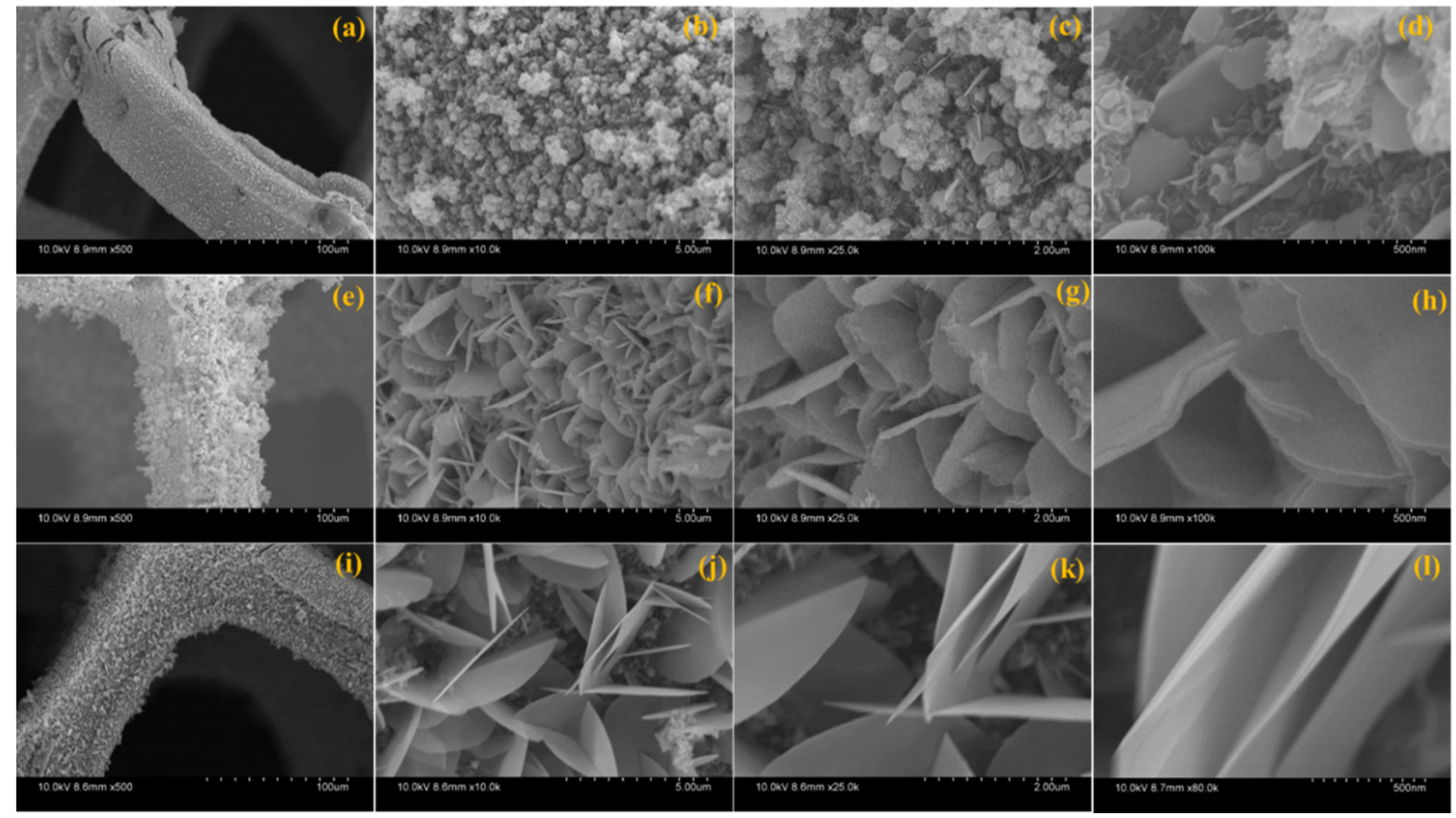

Figure 2. Scanning electron micrographs of MnFe-9 (a-d), CoFe-12 (e-h), and CoFe-24 (i-1) at different magnifications.
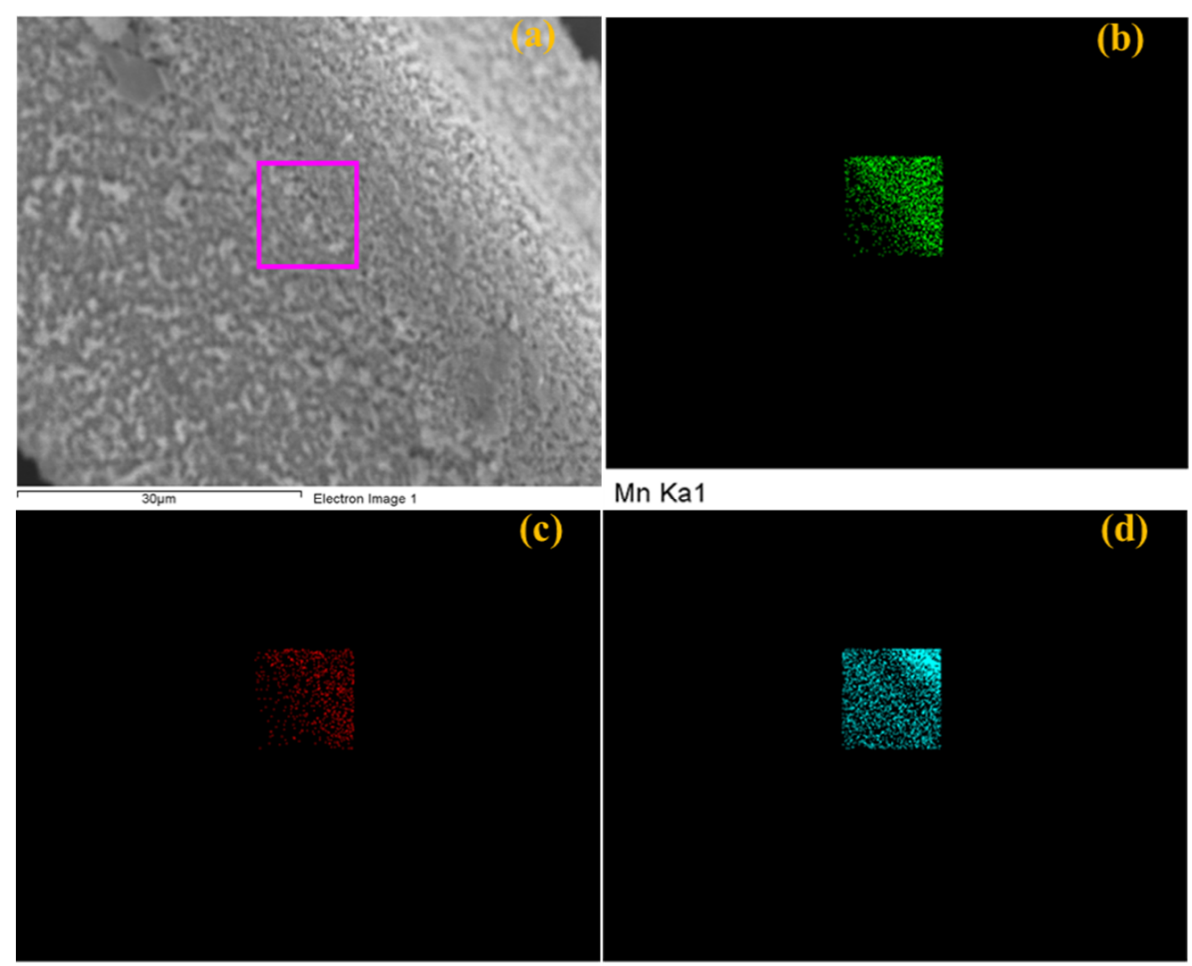

Mn Ka1

Figure 3. EDS element mapping of the MnFe-LDH electron image (a), manganese (b), iron (c), and oxygen (d). 

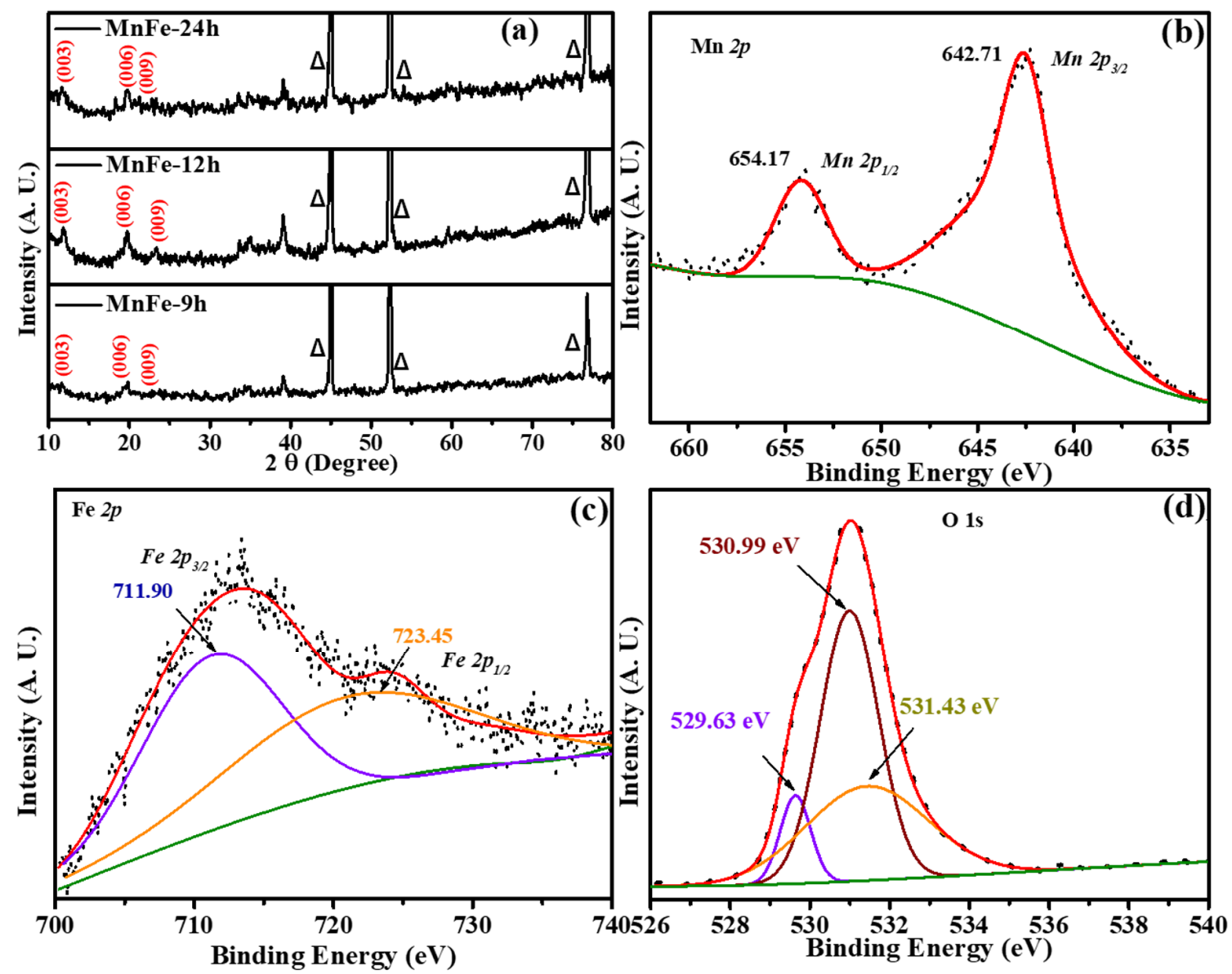

Figure 4. (a) XRD patterns of MnFe-9h, MnFe-12h, and MnFe-24h. High resolution spectra of MnFe-12, (b) Mn 2p, (c) Fe 2p, and (d) O 1s.

\subsection{XPS}

The XPS of MnFe-LDH mainly involve Mn, Fe, and O components, as depicted in Figure 4b-d. The high-resolution Mn 2p core level spectrum (Figure $4 b$ ) consists of two characteristic peaks located at the binding energies of 654.17 and $642.71 \mathrm{eV}$ that are associated with the Mn 2p1/2 and Mn 2p3/2, respectively. For Fe $2 p$ (Figure $4 \mathrm{c}$ ), the peak centered at $711.90 \mathrm{eV}$ belongs to Fe $2 \mathrm{p} 3 / 2$, whereas the peak located at $723.45 \mathrm{eV}$ corresponds to $\mathrm{Fe} 2 \mathrm{p} 1 / 2$, which is consistent with the previously reported literature, indicating the formation of MnFe-LDH [25]. In Figure 4d, for the O 1s spectra, the peaks centered at the binding energies of 529.63, 530.99, and $531.43 \mathrm{eV}$ are associated with the metal-oxygen (M-O), i.e., oxygen in the form of bound hydroxide groups $\left(\mathrm{OH}^{-}\right)$, which signifies the formation of $\mathrm{M}-\mathrm{OH}(\mathrm{M}=\mathrm{Mn}$ or $\mathrm{Fe})$ and surface contamination, respectively [7].

\subsection{Electrochemical Study}

The electrochemical behavior of the MnFe-LDH nanostructured electrodes grown at different hydrothermal reaction times was studied by measuring the CV and GCD curves using a conventional three-electrode system. The CV curves of MnFe-9h, MnFe-12h, and MnFe-24h recorded in the potential window of -0.1 to +0.5 versus SCE at $5 \mathrm{mVs}^{-1}$ are as shown in Figure $5 \mathrm{a}$. The pair of redox peaks observed for all three electrodes (MnFe-9h, MnFe-12h, and MnFe-24h) suggests the faradaic charge storage behavior of MnFe-LDH. It was observed that the area under the curve and, hence, the current from the $\mathrm{CV}$ curve varied with respect to the hydrothermal reaction time, as a clear modification is seen from the FESEM images (Figure 2). With the increase in hydrothermal reaction time from $9 \mathrm{~h}$ to $12 \mathrm{~h}$, the area under the $\mathrm{CV}$ curve increases and the surface morphology changes from nanoparticles with 
few nanosheets to the uniform and well-organized nanosheets, providing more accessible reaction sites to the electrolyte ions. After further increasing the hydrothermal reaction time from $12 \mathrm{~h}$ to $24 \mathrm{~h}$, the observed decrease in the $\mathrm{CV}$ current may be due to the formation of large leaf-like nanostructures covering the active materials, which then resulted in difficult access for the electrolyte ions. According to the previous literature, the shape of the $\mathrm{CV}$ curves obtained for MnFe-LDH electrodes defines the battery-type behavior of the synthesized electrodes; it is thus necessary to also discuss the areal capacitance in terms of areal capacities [26-28]. The areal capacitance values (capacities) calculated from the $\mathrm{CV}$ curves at $5 \mathrm{mVs}^{-1}$ for MnFe-9h, MnFe-12h, and MnFe-24h were $1196 \mathrm{mFcm}^{-2}\left(717 \mathrm{mCcm}^{-2}\right)$, $2013 \mathrm{mFcm}^{-2}\left(1208 \mathrm{mCcm}^{-2}\right)$, and $1802 \mathrm{mFcm}^{-2}\left(1081 \mathrm{mCcm}^{-2}\right)$, respectively.
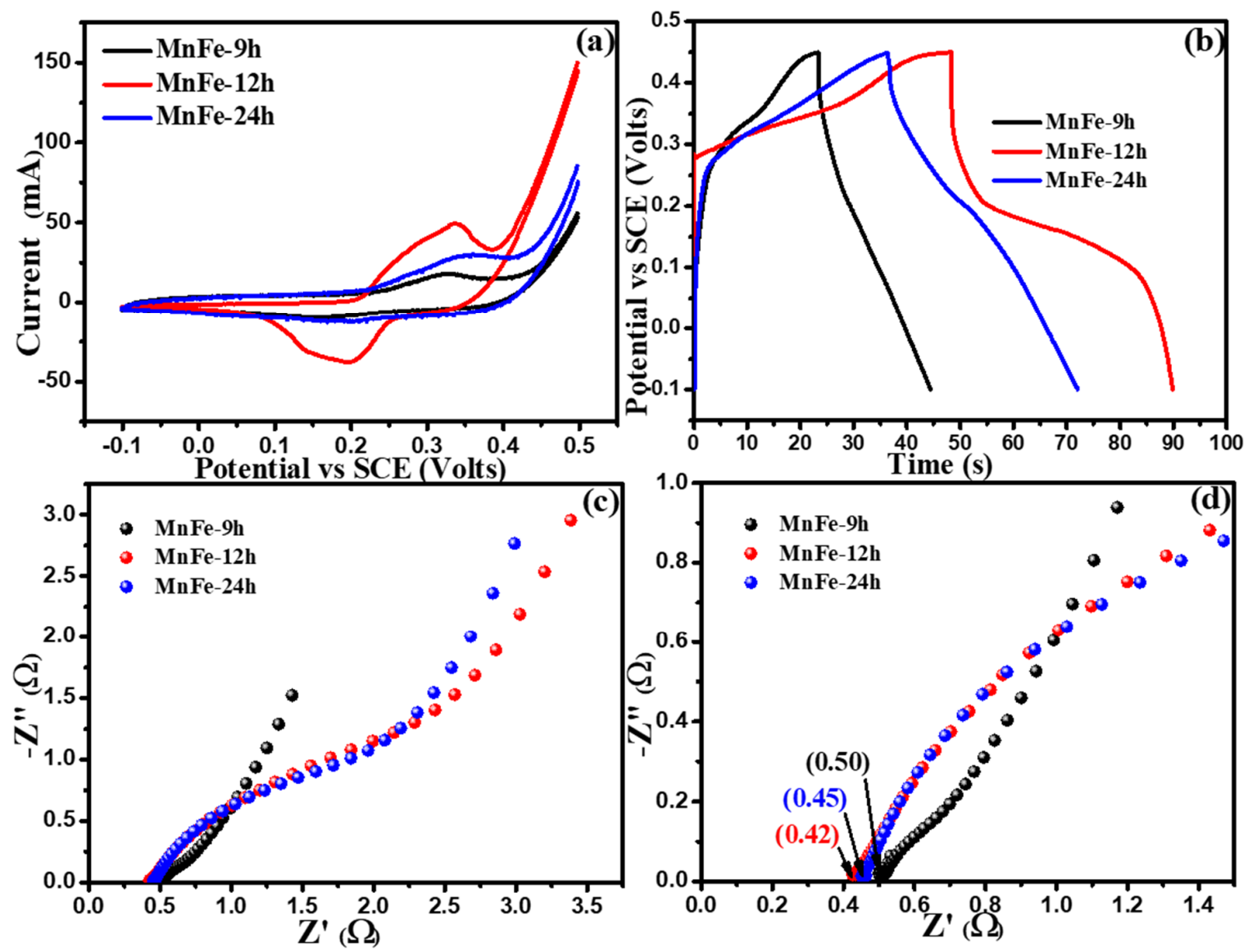

Figure 5. (a) Cyclic voltammetry (CV) curves of MnFe-9h, MnFe-12h, and MnFe-24h, at a scan rate of $5 \mathrm{mVs}^{-1}$, (b) charge-discharge at an applied current of $25 \mathrm{~mA}$, (c) Nyquist plots, and (d) magnified Nyquist plots of the MnFe-9h, MnFe-12h, and MnFe-24h electrodes.

The CV curves of the MnFe-9h, MnFe-12h, and MnFe-24h electrodes recorded with varying scan rates from 5 to $100 \mathrm{mVs}^{-1}$, in a potential window of -0.1 to $+0.5 \mathrm{~V}$ versus SCE, are presented in Figure $6 \mathrm{a}-\mathrm{c}$. Figure $6 \mathrm{~d}$ demonstrates the areal capacitance obtained for MnFe-9h, MnFe- $12 \mathrm{~h}$, and MnFe-24h at different scan rates. The highest areal capacitance (capacities) of $1196 \mathrm{mFcm}^{-2}\left(717 \mathrm{mCcm}^{-2}\right), 2013 \mathrm{mFcm}^{-2}$ $\left(1208 \mathrm{mCcm}^{-2}\right)$, and $1802 \mathrm{mFcm}^{-2}\left(1081 \mathrm{mCcm}^{-2}\right)$ was achieved at $5 \mathrm{mVs}^{-1}$, whereas the values of $310 \mathrm{mFcm}^{-2}\left(186 \mathrm{mCcm}^{-2}\right), 679 \mathrm{mFcm}^{-2}\left(407 \mathrm{mCcm}^{-2}\right)$, and $474 \mathrm{mFcm}^{-2}\left(284 \mathrm{mCcm}^{-2}\right)$ for areal capacitance (capacities) were obtained even at a high scan rate of $100 \mathrm{mVs}^{-1}$ for MnFe-9h, MnFe-12h, and $\mathrm{MnFe}-24 \mathrm{~h}$, respectively. This decrease in capacitance with increasing scan rates is due to the difficulty of diffusing electrolyte ions into the electrodes' internal structure and pores and, hence, the ineffective interaction between electrode and electrolyte occurs. 

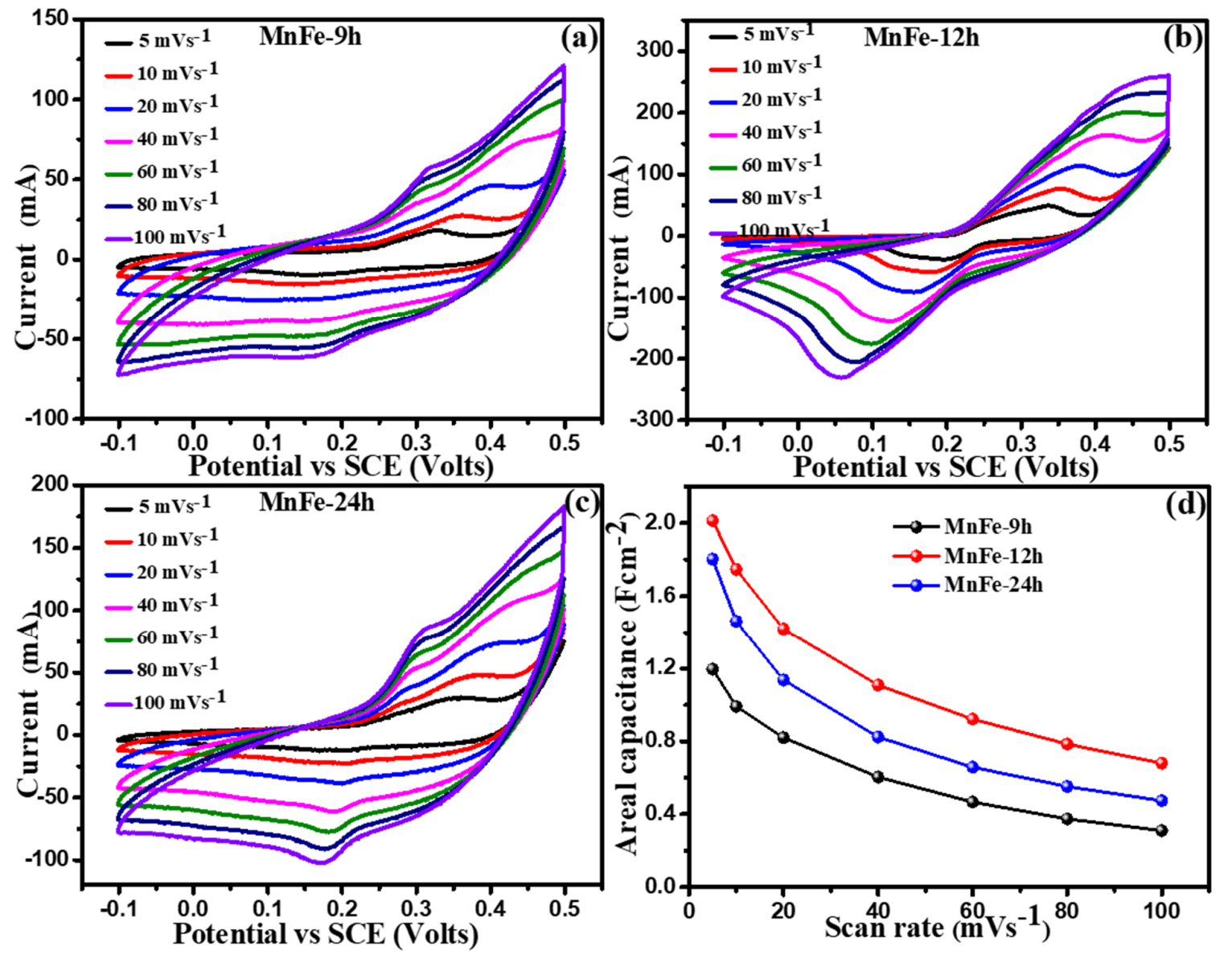

Figure 6. CV curves of (a) MnFe-9h, (b) MnFe-12h, and (c) MnFe-24h, recorded at different scan rates.

(d) Variation of areal capacitance with respect to scan rate.

Figure $5 \mathrm{~b}$ displays the GCD curves of the nanoparticles of all MnFe-LDH electrodes. An analogous observation of the electrochemical behavior compared to $\mathrm{CV}$ of the electrodes is seen from the GCD measurements. The deviation in triangular shape of the GCD curves for all electrodes was observed, again indicating the charging/discharging process was accompanied by electrochemical oxidation/reduction reactions of MnFe-LDH.

From the GCD curves, the maximum areal capacitance (capacities) of $956 \mathrm{mFcm}^{-2}\left(525 \mathrm{mCcm}^{-2}\right)$, $1886 \mathrm{mFcm}^{-2}\left(1037 \mathrm{mCcm}^{-2}\right)$, and $1623 \mathrm{mFcm}^{-2}\left(893 \mathrm{mCcm}^{-2}\right)$ was achieved at an applied current of $25 \mathrm{~mA}$, for MnFe-9h, MnFe-12h, and MnFe-24h, respectively. The GCD curves measured at different the applied currents of 25, 30, 35, and $40 \mathrm{~mA}$ for the MnFe-9h, MnFe-12h, and MnFe-24h electrodes are as presented in Figure 7a-c. Figure $7 \mathrm{~d}$ represents the obtained areal capacitance at different applied currents for MnFe-9h, MnFe-12h, and MnFe-24h. From the above electrochemical studies, it was found that the MnFe-12h electrode exhibits the maximum capacitance (capacity) from the CV and GCD curves. A maximum areal energy density and a power density of $0.16 \mathrm{~mW} \mathrm{~h} \mathrm{~cm}{ }^{-2}$ and $13.75 \mathrm{~mW} \mathrm{~cm}^{-2}$, respectively, at an applied current of $25 \mathrm{~mA}$, were achieved.

All the above obtained results strongly proved the conclusion that the MnFe-LDH's morphological features play a significant role in its electrochemical performance. Initially, for $\mathrm{MnFe}-9 \mathrm{~h}$, the aggregated nanoparticles limit the use of the electrochemically active sites. Likewise, at the maximum hydrothermal reaction time ( $\mathrm{MnFe}-24 \mathrm{~h})$, the formation of large leaf-like nanostructures cover the electro-active sites, thus restricting the interaction between the electrolyte and active material. The uniform, thin, and well-organized nanosheets of MnFe-LDH represent an advantageous nanostructure that offers sufficient electrochemical active sites, improves the electrode-electrolyte interface, and hence boosts the redox reaction rate. 

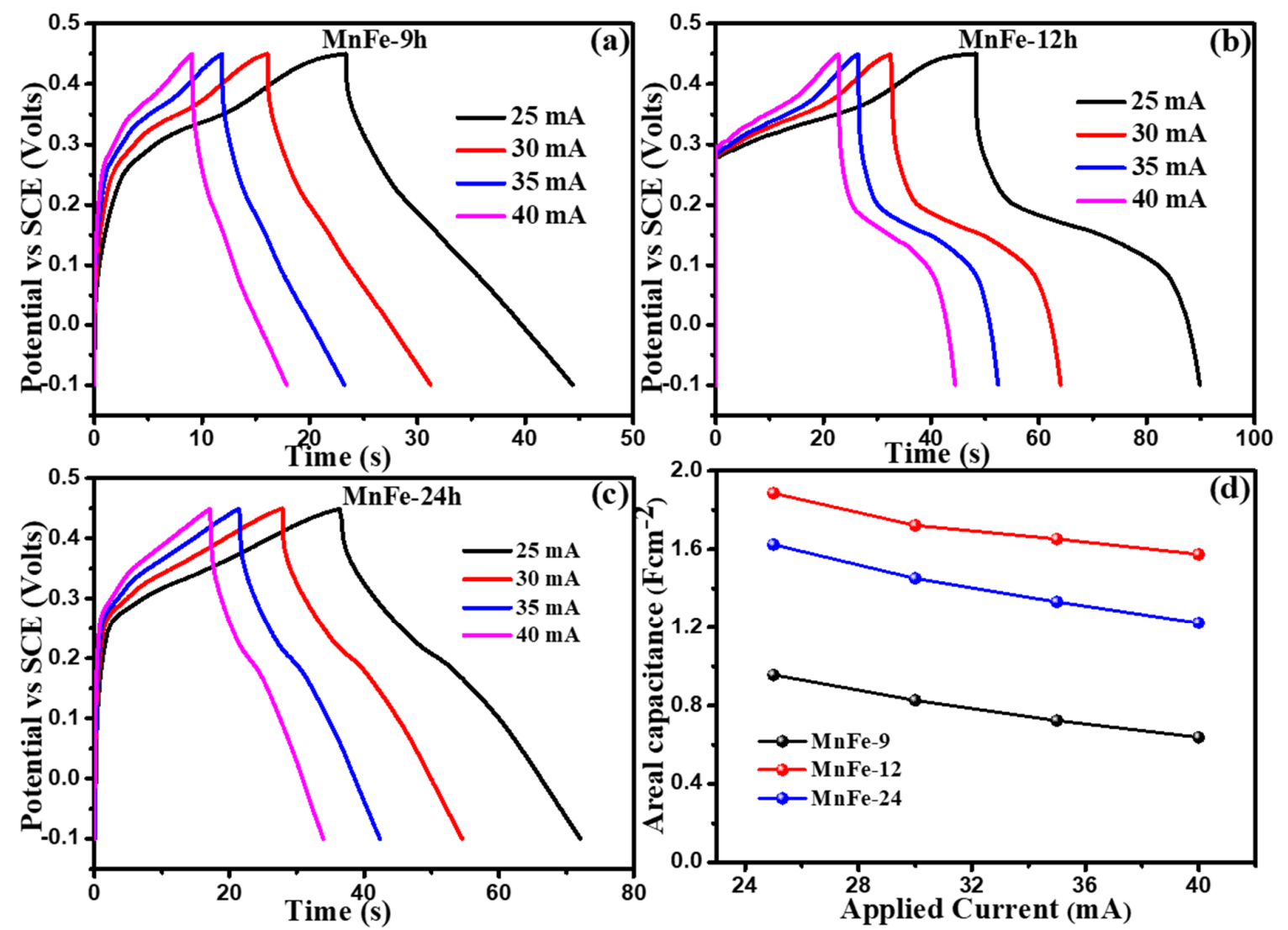

Figure 7. Galvanostatic charge/discharge (GCD) curves of (a) MnFe-9h, (b) MnFe-12h, and (c) MnFe-24h, recorded at different applied currents. (d) Variation of areal capacitance with respect to applied current.

As shown in the Nyquist plots (Figure 5c), the MnFe-9h, MnFe-12h, and MnFe-24h electrodes form a semicircle in the high-frequency region and an inclined straight line in the low-frequency region. The intersection with the $X$-axis towards very high frequency in the Nyquist plot estimates the equivalent series resistance (ESR). The radius of the semicircle can define the charge transfer resistance [5]. The ESR values (from Figure 5f) of the MnFe-9h, MnFe-12h, and MnFe-24h electrodes are 0.50, 0.42, and $0.45 \Omega$, respectively. The radii of the semicircle for MnFe-9h is small (compared to MnFe- $12 \mathrm{~h}$ and MnFe-24h), whereas for the MnFe-12h and MnFe-24h electrodes it is nearly the same. These ESR and charge transfer resistance results suggest the satisfactory electrochemical performance of the $\mathrm{MnFe}-12 \mathrm{~h}$ electrode.

To further evaluate the electrochemical performance of the MnFe-12h electrode in a real application, an asymmetrical cell device was assembled using activated carbon as a negative electrode and MnFe-12h as a positive electrode. The $\mathrm{CVs}$ of both the $\mathrm{AC}$ and $\mathrm{MnFe}-12 \mathrm{~h}$ measured in a three-electrode configuration at a $10 \mathrm{mVs}^{-1}$ scan rate are shown in Figure 8a. The working potentials of the AC and MnFe-12h electrodes were -1.0 to $0 \mathrm{~V}$ and -0.1 to $0.5 \mathrm{~V}$ versus SCE, respectively, which indicates that the operating cell voltage of the $\mathrm{MnFe}-12 \mathrm{~h} / / \mathrm{AC}$ can be $1.6 \mathrm{~V}$. The mass deposited on both the conductors was determined using the charge matching method represented as $\mathrm{Q}^{+}=\mathrm{Q}^{-}$, where $\mathrm{Q}^{+}$and $\mathrm{Q}^{-}$are the positive and negative electrode charges, respectively [29]. Based on this, the mass loading on the positive electrode is $1.1 \mathrm{mg}$, whereas it is $2.1 \mathrm{mg}$ on negative electrode, with a mass ratio of 0.52 . To determine the operating voltage window, the $\mathrm{CV}$ curves of the $\mathrm{MnFe}-12 \mathrm{~h} / / \mathrm{AC}$ asymmetric cell device were measured with an increasing voltage window (from $0-0.3$ to $0-1.7 \mathrm{~V}$ ) as illustrated in Figure $8 \mathrm{~b}$. When increasing the voltage to $1.7 \mathrm{~V}$, some discrete redox peaks were seen, designating deeper redox reactions on the surface of the MnFe-LDH nanosheets. From this, the appropriate voltage window of $0-1.6 \mathrm{~V}$ was achieved for the $\mathrm{MnFe}-12 \mathrm{~h} / / \mathrm{AC}$ asymmetric cell device; beyond this value, polarization becomes visible. Figure $8 \mathrm{c}$ shows the $\mathrm{CV}$ curves of the $\mathrm{MnFe}-12 \mathrm{~h} / / \mathrm{AC}$ asymmetric cell device recorded at scan rates from $10 \mathrm{mVs}^{-1}$ to $100 \mathrm{mVs}^{-1}$ within the optimized voltage window of 0 to $1.6 \mathrm{~V}$. The areal capacitance (capacities) of 
the MnFe-LDH nanosheets increased from $226 \mathrm{mFcm}^{-2}\left(68 \mathrm{mCcm}^{-2}\right)$ with a voltage window of $0-0.3 \mathrm{~V}$ to $3915 \mathrm{mFcm}^{-2}\left(6264 \mathrm{mCcm}^{-2}\right)$ with a voltage window of $0-1.6 \mathrm{~V}$, at a scan rate of $10 \mathrm{mVs}^{-1}$ for the $\mathrm{MnFe}-12 \mathrm{~h} / / \mathrm{AC}$ asymmetric cell device. A maximum areal capacitance (capacities) of $3915 \mathrm{mFcm}^{-2}$ $\left(6264 \mathrm{mCcm}^{-2}\right)$ at $10 \mathrm{mVs}^{-1}$ was achieved, whereas $1354 \mathrm{mFcm}^{-2}\left(2166 \mathrm{mCcm}^{-2}\right)$, even at a high scan rate $100 \mathrm{mVs}^{-1}$, was achieved from the MnFe-12h//AC asymmetric cell device.
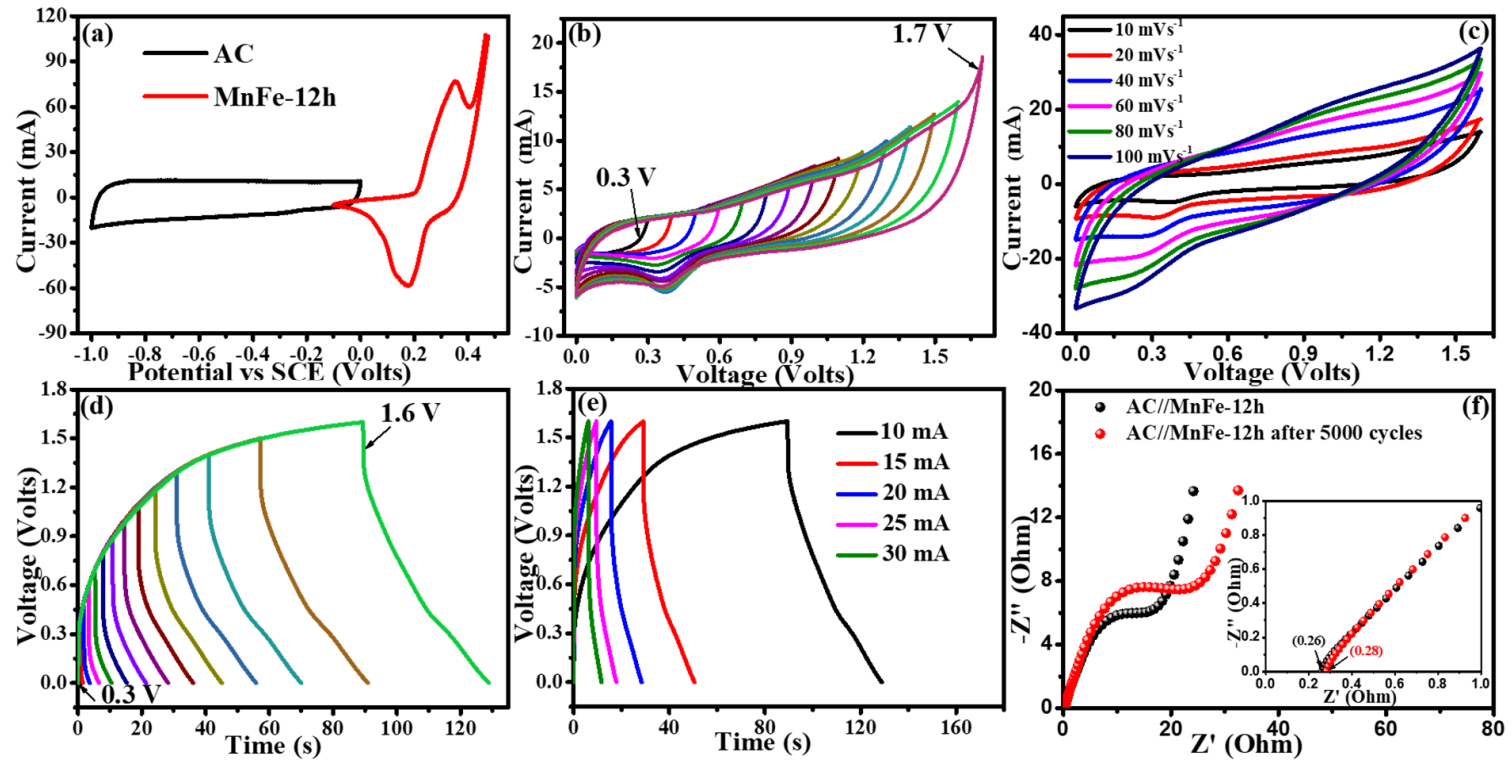

Figure 8. (a) $\mathrm{CV}$ curves of activated carbon and $\mathrm{MnFe}-12 \mathrm{~h}$ electrodes at $10 \mathrm{mVs}^{-1}$. Electrochemical measurements of the MnFe-12h//AC asymmetric cell device; (b) CV and (d) GCD curves at different voltage windows at $10 \mathrm{mVs}^{-1}$ and $10 \mathrm{~mA}$, respectively. (c) CV and (e) GCD curves at different scan rates and applied currents, respectively. (f) Nyquist plot; inset: magnified view of the Nyquist plot.

The GCD curves of the MnFe-12h//AC asymmetric cell also recorded with different applied voltage windows (from 0-0.3 to 0-1.6 V) are presented in Figure 8d. This figure displays the GCD curves of the $\mathrm{MnFe}-12 \mathrm{~h} / / \mathrm{AC}$ asymmetric cell device measured at applied currents from $10 \mathrm{~mA}$ to $30 \mathrm{~mA}$. Little variation in the triangular shape of the GCD curves again represents the occurrence of redox reactions on the surface of the MnFe-LDH nanosheets. The MnFe-12h//AC asymmetric cell device delivers a maximum areal capacitance (capacity) of $506 \mathrm{mFcm}^{-2}\left(809 \mathrm{mCcm}^{-2}\right)$, with an energy density of $44.9 \mu \mathrm{W} \mathrm{h} \mathrm{cm}{ }^{-2}$, and a power density of $16 \mathrm{~mW} \mathrm{~cm}^{-2}$ at an applied current of $10 \mathrm{~mA}$, within the $1.6 \mathrm{~V}$ operating voltage window.

The specific energy and power densities of the MnFe-12h//AC asymmetric cell device obtained at different applied currents are shown in the Ragone plot in Figure 9a. The MnFe-12h//AC asymmetric cell device delivers a maximum specific energy density of $55.01 \mathrm{~W} \mathrm{~h} \mathrm{~kg}^{-1}$, with a power density of $5000 \mathrm{~W}$ $\mathrm{kg}^{-1}$ at an applied current of $10 \mathrm{~mA}$, within the $1.6 \mathrm{~V}$ operating voltage window. The specific energy density and power density values attained in the present study for the MnFe-12h//AC asymmetric cell device are higher than those of previously reported studies for an LDH-based asymmetric cell device, which are depicted in the Ragone plot (Figure 9a) [23,30-39]. To assess the electrochemical stability, the long-term performance of the MnFe-12h//AC asymmetric cell device was investigated by $\mathrm{CV}$ measurements for 5000 cycles at a scan rate of $10 \mathrm{mVs}^{-1}$. Figure $9 \mathrm{~b}$ presents the effect on capacitance retention and areal capacitance of the $\mathrm{MnFe}-12 \mathrm{~h} / / \mathrm{AC}$ device with increasing electrochemical cycle numbers. The inset of Figure $9 \mathrm{~b}$ presents the $\mathrm{CV}$ recorded for the 1st and 5001st electrochemical cycles for the $\mathrm{MnFe}-12 \mathrm{~h} / / \mathrm{AC}$ device at a scan rate of $10 \mathrm{mVs}^{-1}$. The small variation in the $\mathrm{CV}$ curve was observed after performing 5000 cycles, suggesting the slight change in electrochemical performance after performing 5000 cycles. The MnFe-12h//AC cell device exhibited a capacitance retention of approximately 
$93 \%$, with an areal capacitance of approximately $3641 \mathrm{mFcm}^{-2}$, after 5000 cycles, suggesting an excellent and stable electrochemical performance.

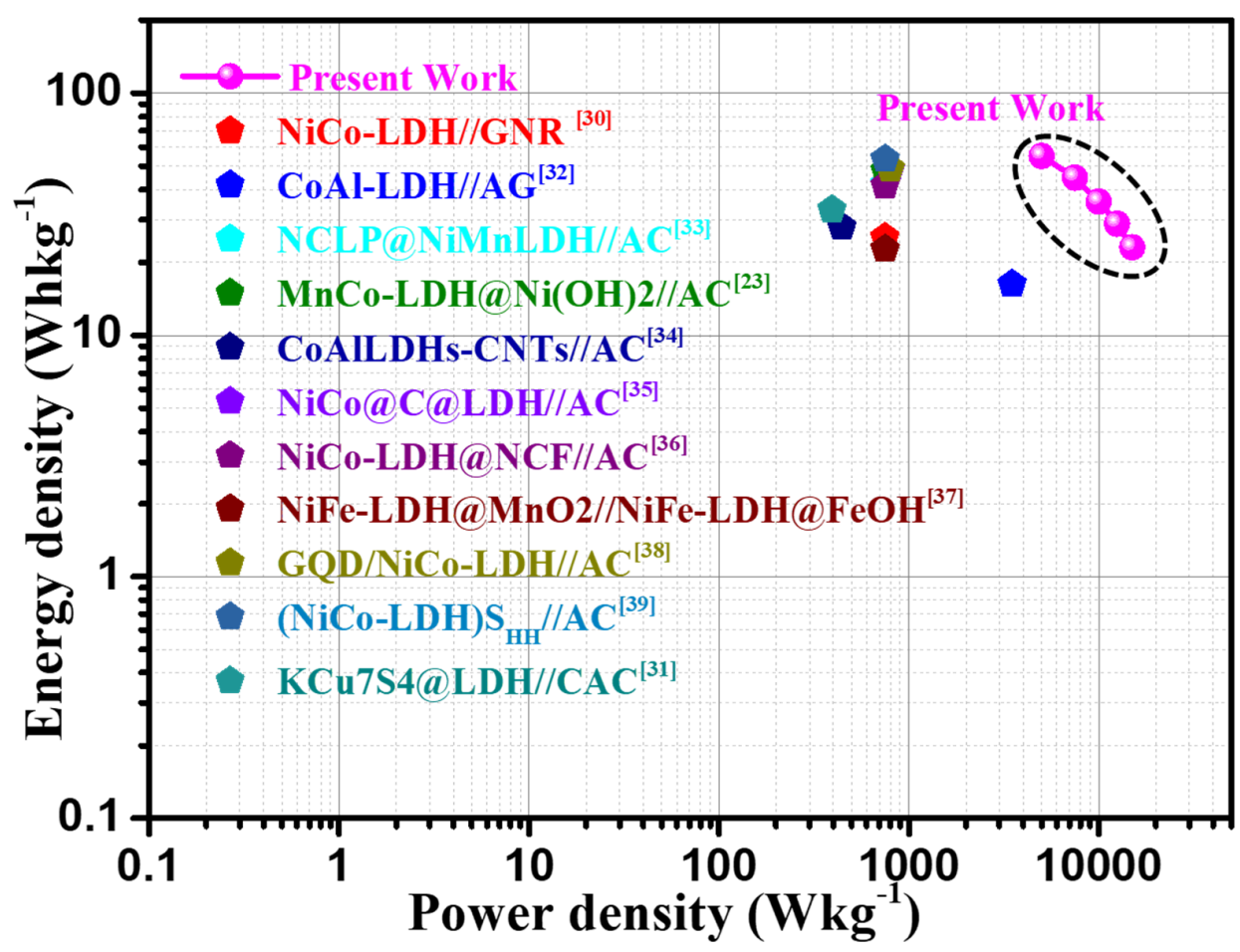

(a)

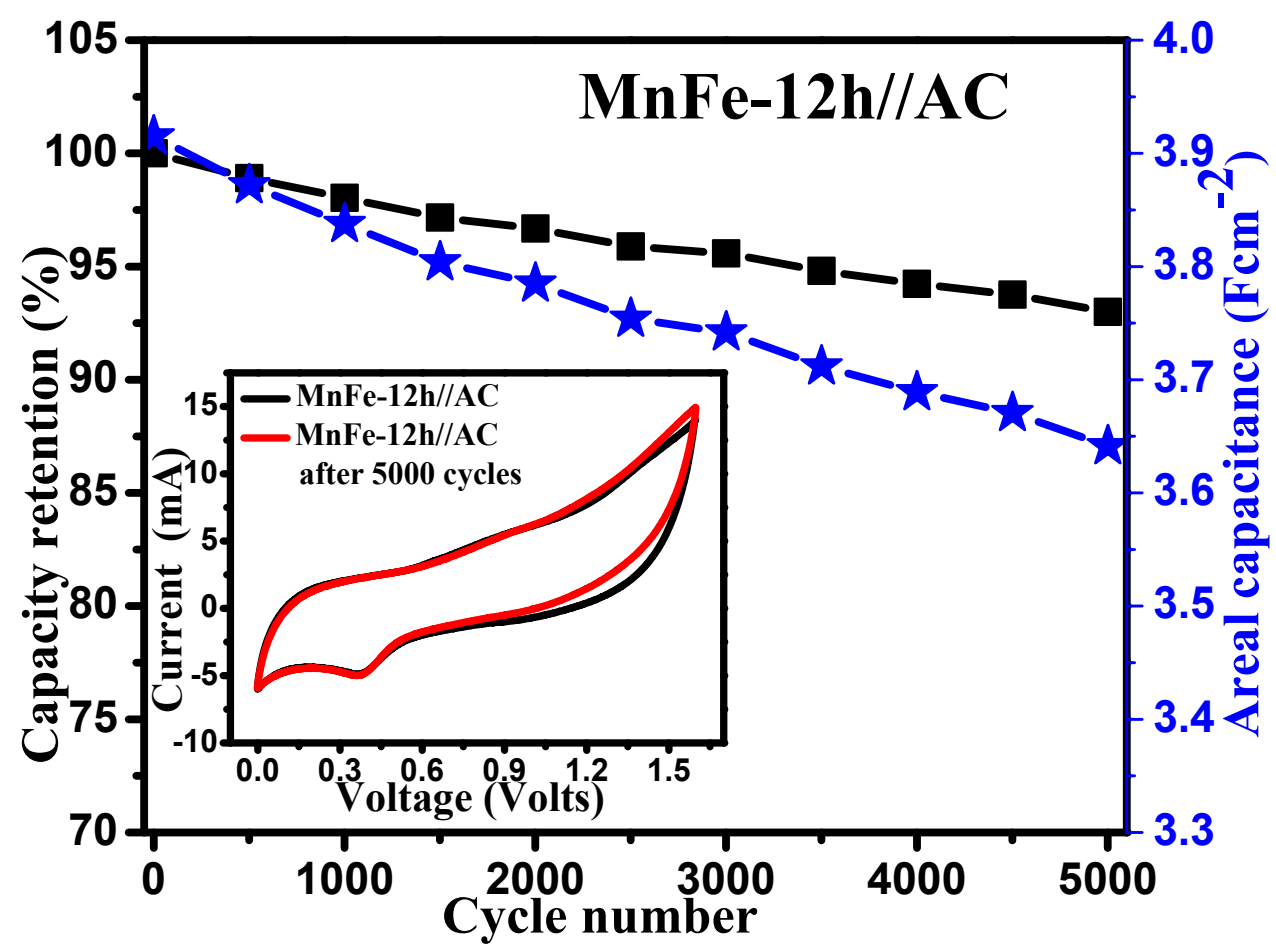

(b)

Figure 9. (a) Ragone plot, for the MnFe-12h//AC asymmetric cell device. (b) Cycling performance of the $\mathrm{MnFe}-12 \mathrm{~h} / / \mathrm{AC}$ asymmetric cell device measured at $10 \mathrm{mVs}^{-1}$. Inset: $\mathrm{CV}$ curves obtained for 1st cycle and 5001st cycles at $10 \mathrm{mVs}^{-1}$. 
The typical Nyquist plots for the AC//MnFe-12h asymmetric cell device before and after performing 5000 cycles are presented in Figure 8f. These Nyquist plots again designate the semicircle toward the high-frequency region and the vertical straight line in the low-frequency region, further suggesting the ideal supercapacitor behavior of the AC//MnFe- $12 \mathrm{~h}$ asymmetric cell device. The inset of Figure $8 \mathrm{f}$ shows the magnified view of the Nyquist plots, denoting the low ESR values, namely 0.26 and $0.28 \Omega$ before and after performing 5000 cycles, respectively. There was a small distinction perceived in the Nyquist plots with a very small change in ESR values $(0.02 \Omega)$ for the AC//MnFe- $12 \mathrm{~h}$ asymmetric cell device after performing 5000 electrochemical cycles, indicating the good stability of the assembled cell device.

\section{Conclusions}

In the present study, we modified the morphological features of MnFe-LDH using the hydrothermal method and examined in detail its supercapacitive electrochemical performance. Our results reveal that the uniform and well-organized MnFe-LDH nanosheets obtained after the $12 \mathrm{~h}$ hydrothermal reaction time afford several active electrochemical sites, effective access to the electrolyte ions, and a minimum resistance path, boosting the electrochemical redox reactions and, hence, enhancing the electrochemical properties. The MnFe-12h//AC asymmetric cell device delivers a maximum capacitance of $506 \mathrm{mFcm}^{-2}$, with an energy density of $44.9 \mu \mathrm{W} \mathrm{h} \mathrm{cm}{ }^{-2}\left(55.01 \mathrm{~W} \mathrm{~h} \mathrm{~kg}^{-1}\right)$ and a power density of $16 \mathrm{~mW} \mathrm{~cm}^{-2}\left(5000 \mathrm{~W} \mathrm{~kg}^{-1}\right)$ at an applied current of $10 \mathrm{~mA}$, (with $93 \%$ capacitance retention after performing 5000 cycles, at $10 \mathrm{mVs}^{-1}$ ) within the $1.6 \mathrm{~V}$ operating voltage window. These encouraging electrochemical characteristics of MnFe-LDH nanosheets offer its feasible use as an electrode material for an efficient energy storage device.

Author Contributions: Conceptualization, D.S.P.; methodology, D.S.P.; software, D.S.P.; formal analysis, D.S.P.; writing-original draft preparation, D.S.P. and S.A.P.; writing-review and editing, S.A.P.; supervision, J.C.S.; project administration, J.C.S. and H.J.K.; funding acquisition, J.C.S and H.J.K. All authors have read and agreed to the published version of the manuscript.

Funding: This study was supported by the National Research Foundation of Korea (NRF-2020R1A2C1015206, NRF-2019M3F5A1A01077146, and NRF-2017M1A2A2048904).

Conflicts of Interest: The authors declare no conflict of interest.

\section{References}

1. Kumar, K.S.; Choudhary, N.; Jung, Y.; Thomas, J. Recent Advances in Two-Dimensional Nanomaterials for Supercapacitor Electrode Applications. ACS Energy Lett. 2018, 3, 482-495. [CrossRef]

2. Wang, F.; Wu, X.; Yuan, X.; Liu, Z.; Zhang, Y.; Fu, L.; Zhu, Y.; Zhou, Q.; Wu, Y.; Huang, W. Latest advances in supercapacitors: From new electrode materials to novel device designs. Chem. Soc. Rev. 2017, 46, 6816-6854. [CrossRef] [PubMed]

3. Majumdar, D.; Maiyalagan, T.; Jiang, Z. Recent Progress in Ruthenium Oxide-Based Composites for Supercapacitor Applications. ChemElectroChem 2019, 6, 4343-4372. [CrossRef]

4. Kumar, S.; Saeed, G.; Zhu, L.; Hui, K.N.; Kim, N.H.; Lee, J.H. OD to 3D carbon-based networks combined with pseudocapacitive electrode material for high energy density supercapacitor: A Review. Chem. Eng. J. 2020, 126352. [CrossRef]

5. Patil, D.S.; Pawar, S.A.; Shin, J.C. Core-shell structure of $\mathrm{Co}_{3} \mathrm{O}_{4} @ \mathrm{CdS}$ for high performance electrochemical supercapacitor. Chem. Eng. J. 2018, 335, 693-702. [CrossRef]

6. Li, X.; Du, D.; Zhang, Y.; Xing, W.; Xue, Q.; Yan, Z. Layered double hydroxides toward high-performance supercapacitors. J. Mater. Chem. A 2017, 5, 15460-15485. [CrossRef]

7. Patil, D.S.; Pawar, S.A.; Shin, J.C.; Kim, H.J. Layered double hydroxide based on ZnCo@NiCo-nano-architecture on 3D graphene scaffold as an efficient pseudocapacitor. J. Power Sources 2019, 435, 226812. [CrossRef]

8. Wang, T.; Zhang, S.; Yan, X.; Lyu, M.; Wang, L.; Bell, J.; Wang, H. 2-Methylimidazole-Derived Ni-Co Layered Double Hydroxide Nanosheets as High Rate Capability and High Energy Density Storage Material in Hybrid Supercapacitors. ACS Appl. Mater. Interfaces 2017, 9, 15510-15524. [CrossRef] 
9. Chen, J.; Wang, X.; Wang, J.; Lee, P.S. Sulfidation of NiMn-Layered Double Hydroxides/Graphene Oxide Composites toward Supercapacitor Electrodes with Enhanced Performance. Adv. Energy Mater. 2016, 6, 1501745. [CrossRef]

10. Yan, M.; Yao, Y.; Wen, J.; Long, L.; Kong, M.; Zhang, G.; Liao, X.; Yin, G.; Huang, Z. Construction of a Hierarchical $\mathrm{NiCO}_{2} \mathrm{~S}_{4} @ P P y$ Core-Shell Heterostructure Nanotube Array on Ni Foam for a High-Performance Asymmetric Supercapacitor. ACS Appl. Mater. Interfaces 2016, 8, 24525-24535. [CrossRef]

11. Liu, S.; Lee, S.C.; Patil, U.; Shackery, I.; Kang, S.; Zhang, K.; Park, J.H.; Chung, K.Y.; Jun, S.C. Hierarchical MnColayered double hydroxides@Ni(OH $)_{2}$ core-shell heterostructures as advanced electrodes for supercapacitors. J. Mater. Chem. A 2017, 5, 1043-1049. [CrossRef]

12. Zhou, H.; Wu, F.; Fang, L.; Hu, J.; Luo, H.; Guan, T.; Hu, B.S.; Zhou, M. Layered NiFe-LDH/MXene nanocomposite electrode for high-performance supercapacitor. Int. J. Hydrog. Energy 2020, 45, 13080-13089. [CrossRef]

13. Bagavathi, M.; Dinesh, B.; Saraswathi, R. A Facile One-Step Electrophoretic Deposition of Co-Ni-Layered Double Hydroxide Nanosheets for a High Performance Supercapacitor. ChemistrySelect 2017, 2, 8799-8806. [CrossRef]

14. Tyagi, A.; Joshi, M.C.; Shah, A.; Thakur, V.K.; Gupta, R.K. Hydrothermally Tailored Three-Dimensional Ni-V Layered Double Hydroxide Nanosheets as High-Performance Hybrid Supercapacitor Applications. ACS Omega 2019, 4, 3257-3267. [CrossRef] [PubMed]

15. Li, M.; Addad, A.; Dolci, M.; Roussel, P.; Naushad, M.; Szunerits, S.; Boukherroub, R. NiMnCr layered double hydroxide-carbon spheres modified Ni foam: An efficient positive electrode for hybrid supercapacitors. Chem. Eng. J. 2020, 396, 125370. [CrossRef]

16. Li, X.; Wu, H.; Guan, C.; Elshahawy, A.M.; Dong, Y.; Pennycook, S.J.; Wang, J. (Ni,Co)Se 2 /NiCo-LDH Core/Shell Structural Electrode with the Cactus-Like (Ni,Co)Se 2 Core for Asymmetric Supercapacitors. Small 2018, 15, 1803895. [CrossRef] [PubMed]

17. Patil, D.S.; Pawar, S.A.; Lee, S.H.; Shin, J.C. CoFe layered double hydroxide for enhanced electrochemical performance. J. Electroanal. Chem. 2020, 862, 114012. [CrossRef]

18. Patil, D.S.; Pawar, S.A.; Ryu, J.; Shin, J.C.; Kim, H.J. Morphological evolution and electrochemical cycling for enhanced electrochemical activity of MnCo-layered double hydroxide. Electrochim. Acta 2020, 331, 135378. [CrossRef]

19. Kurtan, U.; Dursun, D.; Aydın, H.; Toprak, M.S.; Baykal, A.; Bozkurt, A. Influence of calcination rate on morphologies and magnetic properties of $\mathrm{MnFe}_{2} \mathrm{O}_{4}$ nanofibers. Ceram. Int. 2016, 42, 18189-18195. [CrossRef]

20. Huang, G.; Zhang, K.L.; Chen, S.; Li, S.H.; Wang, L.L.; Wang, L.P.; Liu, R.; Gao, J.; Yang, H.H. Manganese-iron layered double hydroxide: A theranostic nanoplatform with $\mathrm{pH}$-responsive MRI contrast enhancement and drug release. J. Mater. Chem. B 2017, 5, 3629-3633. [CrossRef]

21. Ruan, Y.; Jia, X.; Wang, C.; Zhen, W.; Jiang, X. Mn-Fe layered double hydroxide nanosheets: A new photothermal nanocarrier for $\mathrm{O}_{2}$-evolving phototherapy. Chem. Commun. 2018, 54, 11729-11732. [CrossRef]

22. Shi, M.; Narayanasamy, M.; Yang, C.; Zhao, L.; Jiang, J.; Angaiah, S.; Yan, C. 3D interpenetrating assembly of partially oxidized MXene confined Mn-Fe bimetallic oxide for superior energy storage in ionic liquid. Electrochim. Acta 2020, 334, 135546. [CrossRef]

23. Shao, M.; Zhang, R.; Li, Z.; Wei, M.; Evans, D.G.; Duan, X. Layered double hydroxides toward electrochemical energy storage and conversion: Design, synthesis and applications. Chem. Commun. 2015, 51, 15880-15893. [CrossRef] [PubMed]

24. Lu, Z.; Qian, L.; Tian, Y.; Li, Y.; Sun, X.; Duan, X. Ternary NiFeMn layered double hydroxides as highly-efficient oxygen evolution catalysts. Chem. Commun. 2016, 52, 908-911. [CrossRef] [PubMed]

25. Hou, L.; Li, X.; Yang, Q.; Chen, F.; Wang, S.; Ma, Y.; Wu, Y.; Zhu, X.; Huang, X.; Wang, D. Heterogeneous activation of peroxymonosulfate using Mn-Fe layered double hydroxide: Performance and mechanism for organic pollutant degradation. Sci. Total Environ. 2019, 663, 453-464. [CrossRef] [PubMed]

26. Conway, B.E. Electrochemical Supercapacitors: Scientific Fundamentals and Technological Applications; Kluwer Academic Publishers/Plenum Press: New York, NY, USA, 1999. Available online: https://books.google.co.in/books?hl=en\&lr=\&id=zCblBwAAQBAJ\&oi=fnd\&pg=PA1\&dq=B+E+ Conway\&ots=b91Cfg_usx\&sig=MwK895libsqdxTgvTnDx38qntuU\#v=onepage\&q=BEConway\&f=false (accessed on 15 October 2018). 
27. Brousse, T.; Bélanger, D.; Long, J.W. To Be or Not To Be Pseudocapacitive? J. Electrochem. Soc. 2015, 162, A5185-A5189. [CrossRef]

28. Pawar, S.A.; Patil, D.S.; Shin, J.C. Electrochemical battery-type supercapacitor based on chemosynthesized $\mathrm{Cu}_{2} \mathrm{~S}-\mathrm{Ag}_{2} \mathrm{~S}$ composite electrode. Electrochim. Acta 2018, 259, 664-675. [CrossRef]

29. Shao, Y.; El-Kady, M.F.; Sun, J.; Li, Y.; Zhang, Q.; Zhu, M.; Wang, H.; Dunn, B.; Kaner, R.B. Design and Mechanisms of Asymmetric Supercapacitors. Chem. Rev. 2018, 118, 9233-9280. [CrossRef]

30. Jin, H.; Yuan, D.; Zhu, S.; Zhu, X.; Zhu, J. Ni-Co layered double hydroxide on carbon nanorods and graphene nanoribbons derived from MOFs for supercapacitors. Dalt. Trans. 2018, 47, 8706-8715. [CrossRef]

31. Yuan, Y.; Li, Z.; Shi, Z.; Zhu, J. A facile way to grow NiMn-LDH sheets on KCu7S4 nanowires with synergistic effects for applications in hybrid supercapacitors. J. Alloys Compd. 2020, 825, 154056. [CrossRef]

32. Jing, C.; Liu, X.; Yao, H.; Yan, P.; Zhao, G.; Bai, X.; Dong, B.; Dong, F.; Li, S.; Zhang, Y. Phase and morphology evolution of CoAl LDH nanosheets towards advanced supercapacitor applications. CrystEngComm 2019, 21, 4934-4942. [CrossRef]

33. Liang, H.; Lin, J.; Jia, H.; Chen, S.; Qi, J.; Cao, J.; Lin, T.; Fei, W.; Feng, J. Hierarchical NiCo-LDH/NiCoP@NiMnLDH hybrid electrodes on carbon cloth for excellent supercapacitors. J. Mater. Chem. A 2018, 6, 15040-15046. [CrossRef]

34. Yu, L.; Shi, N.; Liu, Q.; Wang, J.; Yang, B.; Wang, B.; Yan, H.; Sun, Y.; Jing, X. Facile synthesis of exfoliated Co-Al LDH-carbon nanotube composites with high performance as supercapacitor electrodes. Phys. Chem. Chem. Phys. 2014, 16, 17936-17942. [CrossRef] [PubMed]

35. Zhu, Y.; Zong, Q.; Zhang, Q.; Yang, H.; Du, W.; Wang, Q.; Zhan, J.; Wang, H. Ultra-long lifespan asymmetrical hybrid supercapacitor device based on hierarchical NiCoP@C@LDHs electrode. Electrochim. Acta 2020, 334, 135589. [CrossRef]

36. Liu, Y.; Wang, Y.; Shi, C.; Chen, Y.; Li, D.; He, Z.; Wang, C.; Guo, L.; Ma, J. Co-ZIF derived porous NiCo-LDH nanosheets/N doped carbon foam for high-performance supercapacitor. Carbon 2020, 165, 129-138. [CrossRef]

37. Sun, Q.; Yao, K.; Zhang, Y. $\mathrm{MnO}_{2}$-directed synthesis of $\mathrm{NiFe}-\mathrm{LDH} @ \mathrm{FeOOH}$ nanosheeet arrays for supercapacitor negative electrode. Chin. Chem. Lett. 2020. [CrossRef]

38. Qiu, H.; Sun, X.; An, S.; Lan, D.; Cui, J.; Zhang, Y.; He, W. Microwave synthesis of histidine-functionalized graphene quantum dots/Ni-Co LDH with flower ball structure for supercapacitor. J. Colloid Interface Sci. 2020, 567, 264-273. [CrossRef]

39. Tahir, M.U.; Arshad, H.; Xie, W.; Wang, X.; Nawaz, M.; Yang, C.; Su, X. Synthesis of morphology controlled NiCo-LDH microflowers derived from ZIF-67 using binary additives and their excellent asymmetric supercapacitor properties. Appl. Surf. Sci. 2020, 529, 147073. [CrossRef] 